\title{
Pre-Extensively Drug-Resistant Tuberculosis
}

National Cancer Institute

\section{Source}

National Cancer Institute. Pre-Extensively Drug-Resistant Tuberculosis. NCI Thesaurus.

Code C128416.

Tuberculosis disease that is caused by a pre-extensively drug-resistant strain of Mycobacterium tuberculosis. 